\title{
SHEAR CAPACITY PREDICTION OF CONFINED MASONRY WALLS SUBJECTED TO CYCLIC LATERAL LOADING
}

\author{
Abdelkrim BOURZAM ${ }^{1}$, Tetsuro GOTO ${ }^{2}$ and Masakatsu MIYAJIMA ${ }^{3}$ \\ ${ }^{1} \mathrm{PhD}$ cand., Kanazawa University (Kakuma-machi, Kanazawa, Ishikawa 920-1192, Japan) \\ E-mail: bourzam@gmail.com \\ ${ }^{2}$ Senior Researcher, Housing Dept. of National Institute of Land and Infrastructures Management (NILIM) of Tsukuba \\ (1, Tatehara, Tsukuba, Ibaraki 305-0802, Japan) \\ E-mail: goto-t92in@nilim.go.jp \\ ${ }^{3}$ Professor, Dept. of Civil Eng., Kanazawa University (Kakuma-machi, Kanazawa, Ishikawa 920-1192, Japan) \\ E-mail: miyajima@t.kanazawa-u.ac.jp
}

\begin{abstract}
This study describes an analytical proposal to predict lateral shear capacity of confined masonry walls that fail by diagonal splitting, where the maximum shear is evaluated as the dowel action of confined columns' reinforcement added to the shear capacity of the plain masonry panel. In order to validate the proposed approach, experimental test results and gathered data from literature were used. The experimental tests concerned two confined clay brick walls subjected to different level of gravity load and cyclic lateral loading. The applicability of some empirical formulae found in literature regarding the stiffness degradation was investigated. Good correlation between the predicted lateral resistance using the proposed approach and all data was achieved.
\end{abstract}

Key Words : confined masonry, brick panel, cyclic load, dowel action, stiffness, shear capacity

\section{INTRODUCTION}

In building masonry system, piers between openings are usually the most vulnerable in case of earthquakes; the failure of walls is due in the majority of cases to shear mechanism. However, it is very important to remedy this weakness by one of the multitude existing solutions as well as reinforcing the masonry panel with steel bars or confining it by tie-columns...etc.

Confined masonry consists of a load-bearing wall surrounded by small cast-in-place reinforced concrete columns and beams called tie-columns (confining columns) and bond-beams or gravity beams, respectively. This system is such that the wall must resist to both, vertical and lateral loads. The R.C tie-columns and bond-beams are intended to confine the masonry panel, thus enhancing the wall deformation capacity to improve the behavior due to a cyclic lateral loading and assure the connections with other walls and floor diaphragms.

The R.C tie-columns and bond-beams should have cross-section dimensions and reinforcement ratios sufficiently enough to resist overturning moments and shear force due to earthquakes. According to the requirements of European $\operatorname{codes}^{1), 2)}$, no contribution of vertical confinement to vertical and lateral resistance should be taken into account in the calculation. The amount of reinforcement is determined arbitrarily on the basis of experience, and depends on the height and size of the building.

In Algerian aseismic code ${ }^{3)}$, the confined masonry walls are assimilated to a triangulated system (truss system), formed by the surrounded tie columns and beams, and the diagonal elements which are constituted by the active struts susceptible to be formed in the masonry.

As known, flexural failure is favored in seismic resistant design because it is accompanied by large plastic deformation and energy absorption and dissipation capacities ${ }^{4}$. Shear failure, on the other hand, is more brittle with limited ductility, from where, confining the plain masonry can remedy in a certain extent this weakness.

Few experimental investigations have been carried out so far on the seismic behavior of confined ma- 
sonry walls and buildings, from which reliable empirical calculation procedures for the design of confined masonry wall panels have been developed.

By testing a series of single storey masonry houses with dynamically imposed sinusoidal displacements with increasing amplitudes, it has been concluded that vertical tie-columns significantly improve the ductility of masonry buildings, but have little effect on the lateral resistance ${ }^{5)}$. Similar conclusions have been obtained by static cyclic tests ${ }^{5), 6), 7)}$. Correlation studies between the behavior of plain masonry wall panels with poor quality masonry and the confined ones have also been conducted ${ }^{8), 9)}$, showing the improved seismic behavior of confined masonry elements. However, no attempt has been made to analytically predict the seismic behavior of confined masonry walls until $1997^{10)}$. In this respect, Tomaževič and Klemenc ${ }^{11)}$ proposed a method to predict the shear capacity of confined masonry walls, where the seismic behavior of piers is modeled by considering the effect of interaction forces between bond-beam, tie-columns and masonry panel, with the effect of vertical tie-columns (dowel action). In this approach, the shear force coming from lateral reinforcement (stirrups) composing the tie-columns was not considered in the calculation. A careful computation of the shear forces of the same specimens, using the same equations developed by these authors, revealed an overestimation in the shear resistances (experimental shear forces) from $23.6 \%$ to $53.8 \%$ (depending on tested specimen ${ }^{11)}$ ). This large overestimation is due principally to the interaction effect between tie columns and brick panel as was introduced by the authors ${ }^{11)}$. However, the authors have simulated the same principle of interaction in the case of the infill wall to the confined masonry system only by changing the interaction coefficient, whereas, the confined wall behavior is totally different from the infill wall construction system.

In 2003 and 2006 Hori et al. ${ }^{12), 13)}$, proposed an analytical approach on seismic resistance of confined concrete block masonry walls, where, the authors adopted a rigid body spring model; the resisting mechanism of the structural system on the lateral load, was a combination of the tension force in the tension side of tie column and the inclined compressive force in a concrete block masonry wall.

In this research work, the main idea of Tomaževič and Klemenc ${ }^{11)}$ (combination of the shear resistance of masonry panel and tie columns) was maintained but excluding the interaction effect, and by another attempt, a new analytical approach to predict the shear resistance of confined masonry walls which fail by diagonal splitting is developed herein to be consistent to a certain extent with the results of the experimental data.
This study consists mainly of two parts. The first part deals with the elaboration of an approach which leads to predict the maximum shear capacity of confined masonry walls, where the total shear of the wall is taken as the summation of the brick panel shear capacity and the shear supported by the R.C confinements (tie-columns). In this method the brick panel is considered as a homogeneous and isotropic material, the basic equation for the evaluation of the shear resistance of plain masonry walls can be derived by taking into account the assumptions of the elementary theory of elasticity. The tie-columns resistance is formulated from the dowel action of R.C confinement vertical bars and stirrups effect. The second part concerns the validation of the proposed approach according to an experimental study and gathered data from literature. The experimental study was conducted on two full scale confined clay brick walls CM30J-1 and CM30J-2, where the specimens were subjected to different levels of gravity load 0.4 $\mathrm{MPa}$ and $1.4 \mathrm{MPa}$, respectively, and in-plane cyclic lateral loads. The specimen CM30J-1 was tested by the authors recently, while the other specimen (CM30J-2) similar to the first one was tested in March $1993^{14)}$. The collected data from different published works represent various confined masonry walls of different characteristics as given in Table 3, where the masonry material properties, the column section, the reinforcing details the height to length ratio $h / l$ and the gravity load are presented. The study also includes an evaluation of the stiffness degradation of walls. Furthermore, to verify the effectiveness of empirical formulae of Tomaževič and Klemenc ${ }^{11)}$ regarding the stiffness degradation, the experimental data of the same authors obtained by testing three 1:5 model scaled of confined masonry walls (AH-1, $\mathrm{AH}-2$ and $\mathrm{AH}-3$ ) with an $h / l$ ratio equals to 1.5 and carrying a gravity load of $0.28 \mathrm{MPa}$, and the current test results of the specimens CM30J-1 and CM30J-2 were used (refer to Table 2).

\section{TEST SPECIMEN AND MECHANICAL CHARACTERISTICS OF USED MATE- RIALS}

As known in masonry construction system, two major types of shear failure can occur:

- Shear failure by diagonal splitting

- Shear failure by mortar-joint separation

In this study, only the case of failure by diagonal splitting is investigated. In such mechanism of rupture, it is permitted to assume the brick panel as a homogenous material as reported in the majority of 


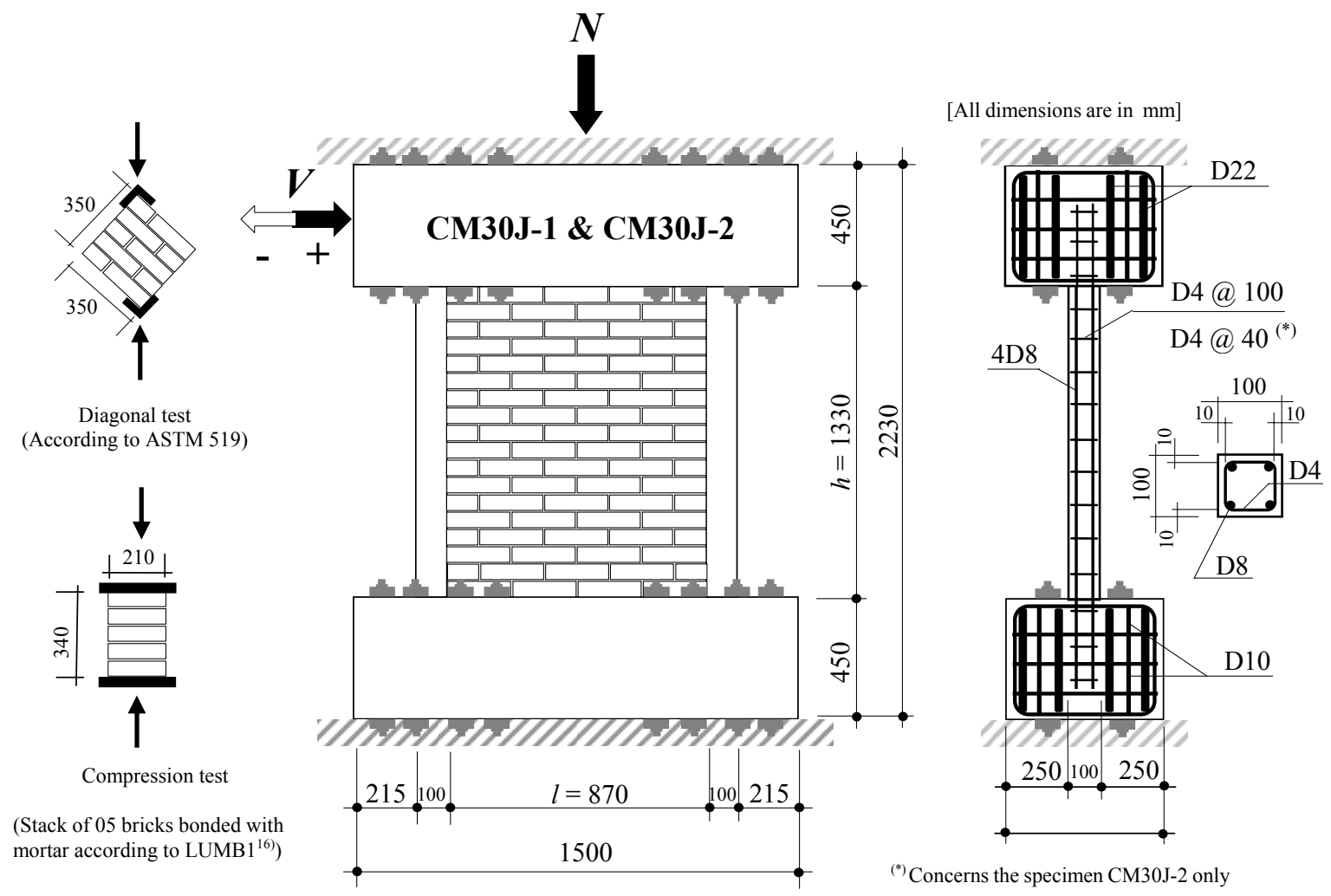

Fig. 1 Test specimens.

earthquake resistant codes (e.g., ancient design codes, or more recently, Eurocode $6^{1)}$ ), Moreover, according to the elementary theory of elasticity, the influence of the tensile strength of the masonry panel $f_{t}$ which is related to the brick unit and mortar qualities, the shape factor $\beta$, the gravity load effect $\sigma_{N}$ and the cross section of the masonry $A_{m}$ affect the shear resistance of the brick panel as shown in the Eq. (3a). When an important gravity load $\sigma_{N}$ is applied to the wall, then, the compressive strength $f_{m}$ of the masonry is introduced into the formulation of the shear resistance (Eq. (3b)). As for the effect of tie columns, the action of the brick panel on both tie-columns creates dowels in the columns' toes from where the resulting shear resistance is added to the shear of the brick panel (see Eqs. (9a) and (9b)).

In the case of masonry walls which fail by joint separation and/or by shear occurs in the beds of mortar, the hypothesis of homogeneity is not relevant anymore and leaves room to the heterogeneity dominance, where the bond stress between bricks and mortar, the shear of the mortar itself, the tensile strength of the brick units...etc, should be taken into account when assessing the shear resistance of the brick panel. The failure of the brick wall by joint separation or by shear in the beds of mortar is usually occurs when a poor quality of mortar (with small compressive and small shear strengths) is used to construct the wall and/or the gravity load is very small or null.
Despite of the high costs and the difficulties of carrying out the experimental work in the laboratory, experiments remain incontestably imperative for identifying the mechanical behavior of this structural system.

The test specimens CM30J-1, CM30J-2 as introduced before, are the full scale of a common window pier with $h / l$ ratio equal to 1.5 surrounded by RC ties. The panel of walls was composite of Japanese solid clay brick units with $210 \times 100 \times 60 \mathrm{~mm}$ of nominal dimensions and a characteristic compressive strength of $30 \mathrm{MPa}$. The bricks were laid with plain cement mortar, with a joint thickness of $10 \mathrm{~mm}$ and $27 \mathrm{MPa}$ of compressive strength.

The concrete used for surrounding frame had a compressive strength of $20 \mathrm{MPa}$. The yielding stress of principal bars (vertical reinforcements) of the specimen CM30J-1 was $415 \mathrm{MPa}$ and $600 \mathrm{MPa}$ for stirrups steel, and $385 \mathrm{MPa}$ for all the steel used in the case of specimen CM30J-2. Details of dimensions and arrangement of reinforcement of specimens and member sections are shown in Fig.1.

The wall is erected on an RC beam foundation. A similar beam is cast in place on the top of the wall after constructing the brick panel and the RC tie columns. This beam permits a sufficient anchorage of the vertical reinforcing bars in both columns and provides also an adequate transfer of the applied horizontal load to the wall. The RC beams are bolted to the reaction frame as shown in the Fig.2. 


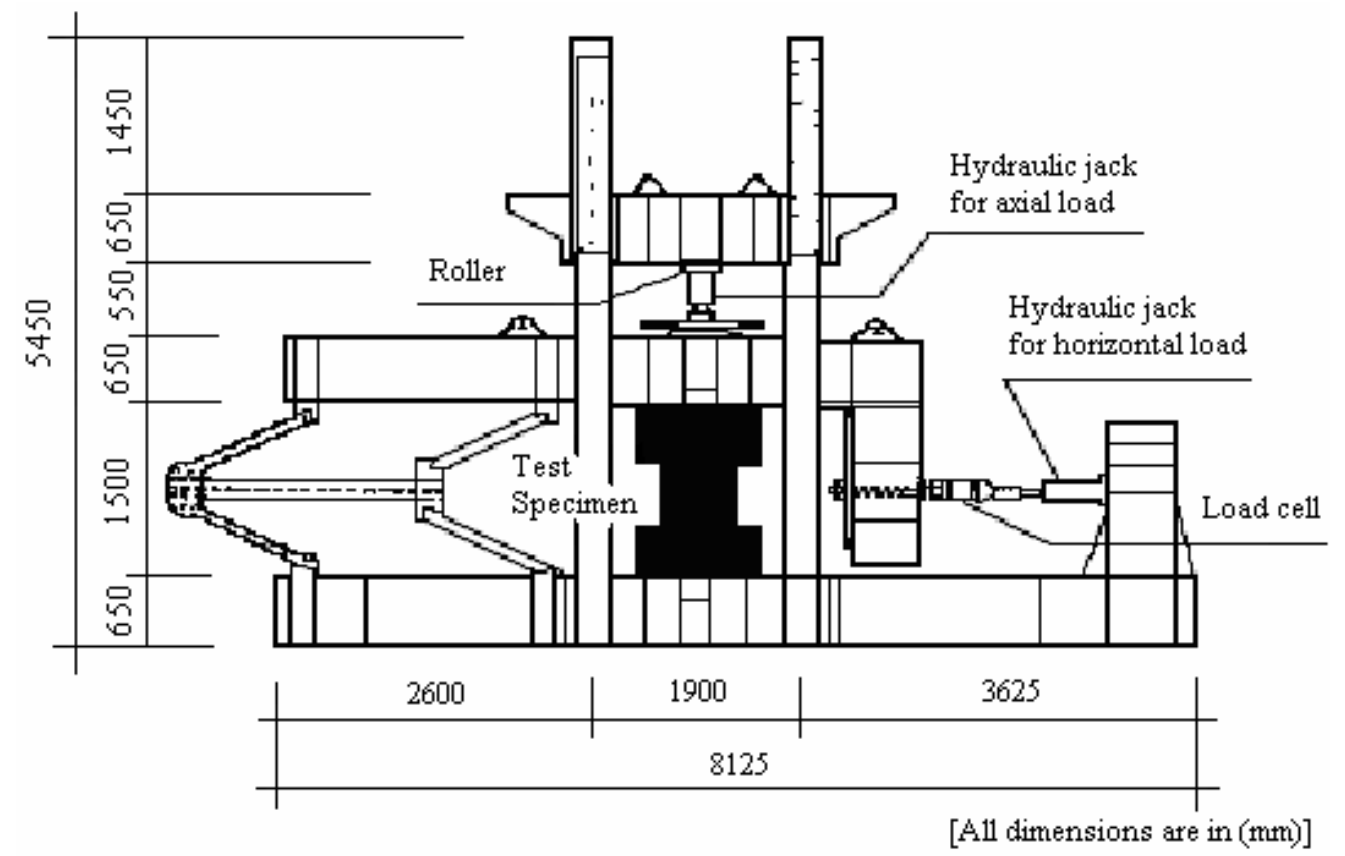

Fig. 2 Loading system.

The compressive strength of masonry $f_{m}^{\prime}$ is equal to $9 \mathrm{MPa}$ obtained by testing three stack bonded prisms of five bricks each and jointed between them on the building face by $10 \mathrm{~mm}$ of mortar according to the specifications of LUMB ${ }^{16)}$.

The masonry tensile strength $f_{t}$ is obtained by testing three masonry square prism specimens (350x350x100 mm) under diagonal compression load as specified by ASTM 519 (ASTM C1391). The value of the tensile strength $\left(f_{t}=1.1 \mathrm{MPa}\right)$ is evaluated as the principal tensile stress in the center of the $\operatorname{prism}^{15), 17), 18)}$ which is equal to $0.7336 \tau$ where $\tau=$ $0.707 P_{d} / A$ is the average shear stress in the prism $\left(P_{d}\right.$ and $A$ are the maximum diagonal compressive load and the prism section, respectively).

Modulus of elasticity and shear modulus of masonry and concrete, determined at $1 / 3$ of compression strength, were $E_{m}=8241 \mathrm{MPa}, G_{m}=1723 \mathrm{MPa}$ and $E_{c}=18320 \mathrm{MPa}, G_{c}=7633 \mathrm{MPa}$, respectively.

\section{LOADING SYSTEM AND MEASURE- MENT}

The test on the confined masonry walls (CM30J-1 and CM30J-2) was carried out using the testing facilities for structural member tests of B.R.I (Building Research Institute-Japan) as shown in Fig.2. The vertical and horizontal actuators exert forces self-controlled by computer. Two Transducers of LVDT type were used to measure the lateral displacement.
During the test process, the vertical pressure generated by the vertical actuator, the steel loading beam and the top RC beam is set equal to $0.4 \mathrm{MPa}$ for the specimen CM30J-1 and 1.4 MPa for the specimen CM30J-2. The first moderate gravity load of $0.4 \mathrm{MPa}$ represents the resulting average load at the first floor of a four-story building, whereas the value of 1.4 MPa representing an important gravity load involves a stockroom or a special infrastructure.

The cyclic loading test applied to specimens was considered as a quasi-static test.

Cyclic horizontal displacements of increasing amplitude have been imposed to the wall and expressed in drift angle, the first value is of $1 / 3200$ and the latest one corresponds to the rupture of the wall. Two loading cycles were performed at each amplitude.

The hysteresis loops, showing the relationship between the measured lateral load and the average horizontal displacements for the tested wall CM30J-1 are shown in Fig.3.

\section{EXPERIMENTAL RESULTS AND OB- SERVED MECHANISM}

Test behavior of specimen CM30J-1 experienced different stages. During the third cycle of loading which corresponds to a drift angle of $1 / 1600$, and at lateral load $V=-66.25 \mathrm{kN}$ and horizontal displacement $\delta=-0.49 \mathrm{~mm}$, a small bending cracks appeared horizontally at the basis of the left RC tie. At about the same loading level during the fourth cycle $(V=$ 


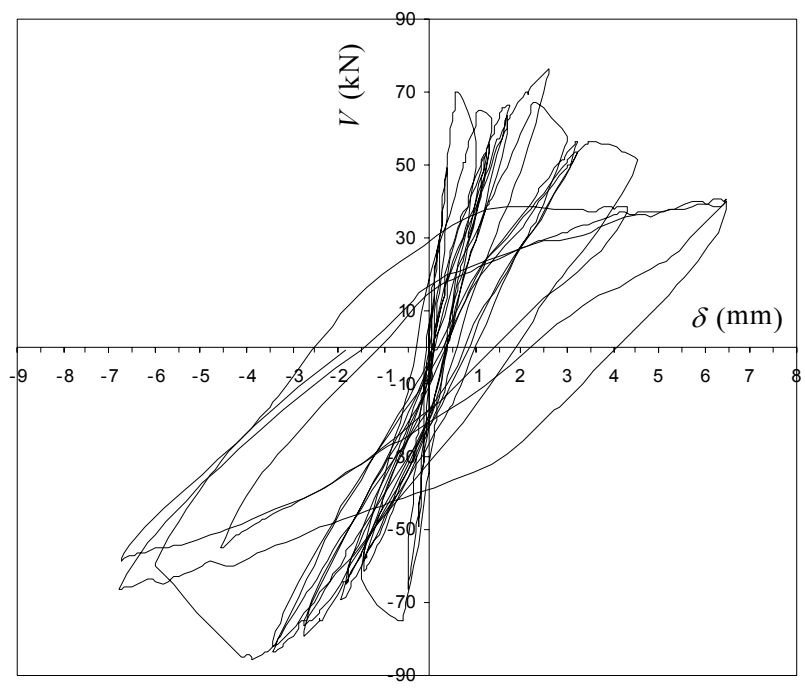

Fig. 3 Lateral load-displacement hysteresis loops of CM30J-1.

$70.25 \mathrm{kN}, \delta=0.6025 \mathrm{~mm}$ ), other small cracks appeared at the interface of the brick panel and the left tie-column, as well as a diagonally oriented cracks were observed on the strut of the wall as mentioned in the Fig.4. Symmetric cracks were created quickly by a negative loading within the same level of drift angle. By definition this step marks the crack limit (elastic limit) of the wall.

The followed cracks propagated and spread similarly to the crack pattern which initiated at the elastic limit.

The maximum lateral load was recorded in the ninth cycle which corresponds to the story drift angle of $1 / 500$. The average values of the maximum shear load and its corresponding horizontal deflection obtained at loading in positive and negative direction were $78 \mathrm{kN}$ and $2.67 \mathrm{~mm}$, respectively.

The ductile behavior of the wall was confirmed by the large horizontal displacements and the decreasing of the lateral load in the last loading cycles as shown in the Fig. 3. The CMOD (Crack Mouth Opening Displacement) of the diagonal cracks became important and the cracks passed through the tie-columns to form the corner-to-corner diagonal shear cracks.

Regarding the specimen CM30J-2, the gathered data ${ }^{14)}$ contain only three limit state data, the lateral load $V_{e l}=101.4 \mathrm{kN}$ and displacement $\delta_{e l}=0.61 \mathrm{~mm}$ at the elastic limit state, the maximum resistance $V_{W}$ $=160.5 \mathrm{kN}$ and its corresponding horizontal displacement $\delta_{W}=2.5 \mathrm{~mm}$ and finally, the last state characterized by a lateral resistance $V_{f}=72.13 \mathrm{kN}$ and a maximum displacement before the collapse of the wall $\delta_{f}=12 \mathrm{~mm}$. The specimen CM30J-2 with an applied different gravity load underwent shear failure in the same way as experienced by the specimen CM30J-1. In other words, the failure occurred also by

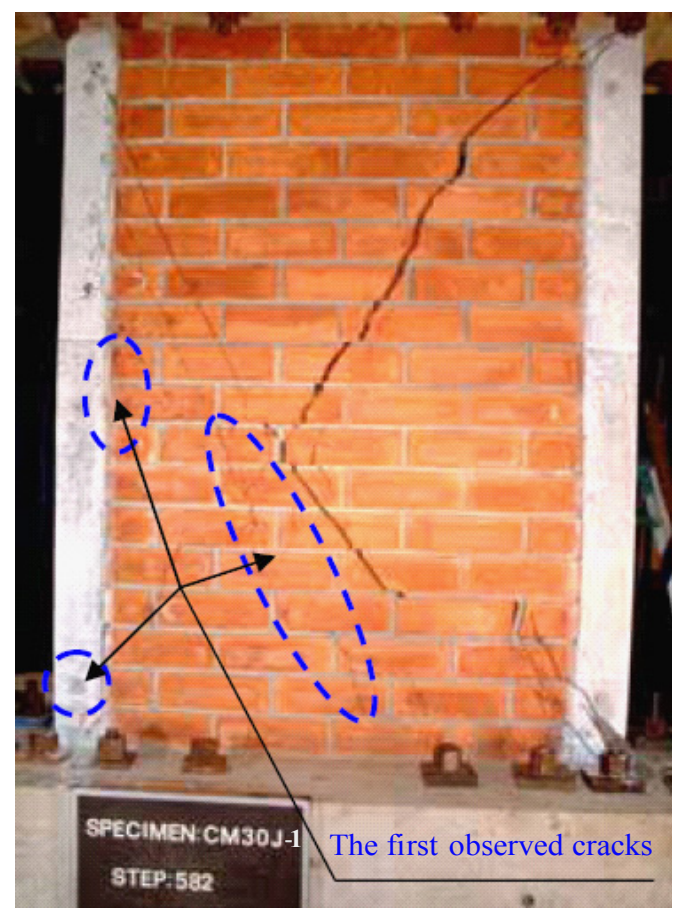

Fig. 4 Final crack pattern of the wall CM30J-1.

splitting and the crack pattern of the wall was similar to the one of the specimen CM30J-1 as shown in Fig. 4.

\section{ANALYTICAL PREDICTION OF SHEAR CAPACITY AND STIFFNESS DEGRA- DATION}

The development of practical methods for evaluating the shear strength of bearing confined masonry walls is a difficult task since experimental and analytical data of its mechanical behavior are less numerous and their interpretations are less precise. Indeed, the diversity of the available material and the imperfection of its production techniques make it complex to characterize and normalize this type of construction material.

Most of the research works and the existing regulations such as the Eurocode $6^{1)}$ applied to the construction industry, simplify the behavior of the masonry with the aim to provide practical and easier criteria for the analysis of the structural behavior. In general, these regulations recommend the use of a linear model by considering the masonry such as a homogeneous material ${ }^{1), 15)}$.

The approach presented in this paper leads to predict analytically the maximum shear capacity of confined masonry walls expressed as the sum of the brick panel shear capacity and the shear supported by the R.C tie-columns. The proposed method deals 
with the confined masonry walls which fail by diagonal splitting only (failure by joint separation is out of the scope of this study).

\section{(1) Shear capacity of confined masonry walls a) Brick panel contribution}

According to an alternative theory, it is assumed that diagonal cracks at shear failure are caused by the principal tensile stresses or by the combination of both principal stresses which develop in the plane of the wall when subjected to both vertical and lateral load ${ }^{4), 10), 15)}$. With these assumptions, the development of diagonally oriented cracks, passing through masonry units in the case of a brick masonry wall is easily explained.

By considering the masonry wall as an elastic, homogeneous and isotropic structural element, the basic equation for the evaluation of the shear resistance of plain masonry walls can be derived by taking into account the assumptions of the elementary theory of elasticity ${ }^{19}$. Under the combination of a vertical load $N$ and a lateral load $V$, the principal stresses of compression and tension $\sigma_{c}$ and $\sigma_{t}$ are developed in the middle section of the wall as following:

$$
\begin{gathered}
\sigma_{t}=-\frac{\sigma_{N}}{2}+\sqrt{\left(\frac{\sigma_{N}}{2}\right)^{2}+(\beta \tau)^{2}} \\
\sigma_{c}=\frac{\sigma_{N}}{2}+\sqrt{\left(\frac{\sigma_{N}}{2}\right)^{2}+(\beta \tau)^{2}}
\end{gathered}
$$

Where;

$\sigma_{N}=$ the average compression stress on the brick panel due to vertical load $N$.

$\beta=$ the shear stress distribution factor depends of the height to length ratio $h / l$ of the brick panel $(\beta=1$ for $h / l \leq 1, \beta=h / l$ for $1<h / l<1.5$ and $\quad \beta$ $=1.5$ for $h / l \geq 1.5)^{10)}$.

$\tau=V / A_{m}$ the average shear stress due to lateral load

$V$ and $\beta \tau$ represents the maximum shear stress at the neutral axis of the panel.

$A_{m}=$ the horizontal cross section area of the masonry panel.

With the same hypothesis mentioned above, when the maximum resistance $V$ is reached $\left(V=V_{m}, \tau=\tau_{m}=\right.$ $\left.V_{m} / A_{m}\right)$, the referential principal tensile stress that would develop at that instant is called the tensile strength of masonry $\left(f_{t}\right)$.

$$
f_{t}=\sigma_{t}=-\frac{\sigma_{N}}{2}+\sqrt{\left(\frac{\sigma_{N}}{2}\right)^{2}+\left(\beta \frac{V_{m}}{A_{m}}\right)^{2}}
$$

Where the lateral resistance of a plain masonry wall panel $V_{m}$ failing in shear by critical tensile strength is obtained from the Eq.(2) as follows:

$$
V_{m}=A_{m} \frac{f_{t}}{\beta} \sqrt{\frac{\sigma_{N}}{f_{t}}+1}
$$

According to this hypothesis (failure by critical tensile strength), the wall would fail if the principal tensile stress $\sigma_{t}$ exceeds the tensile strength of the brick panel ${ }^{10), 15)}$. This hypothesis could be considered in case of:

- Small to moderate gravity load supported by masonry wall (case of low rise buildings and traditional dwellings). Based on the Peruvian masonry code ${ }^{20)}$ for masonry buildings exterior walls

$\sigma_{N} \leq 0.5 \mathrm{MPa}$.

- Failure is brittle and occurred by splitting not by joint separation ${ }^{15)}$.

- Diagonal cracking is initiated at or near the neutral axis of the piers (wall) and spread diagonally ${ }^{4), 15), 19)}$.

In such hypotheses the contribution of the compressive strength of masonry $f_{m}$ is neglected, where the Eq. (3a) becomes less accurate in case of an important gravity load supported by the masonry wall (case of stockroom or a special infrastructure). Without any specification toward the level of gravity load, Yokel and Fattal ${ }^{15)}$, and Sucuoğlu and McNiven ${ }^{4)}$ considered that both principal stresses in the plane of the wall contribute to the failure ${ }^{4)}$ and their combination satisfies the Mohr-Coulomb failure theory ${ }^{19}$. Based on these considerations the lateral resistance will be expressed by:

$$
V_{m}=\frac{A_{m}}{\beta\left(1+\frac{f_{t}}{f_{m}^{\prime}}\right)} \sqrt{f_{f}^{2}+\sigma_{N} f_{t}\left(1-\frac{f_{t}}{f_{m}^{\prime}}\right)-\sigma_{N}^{2} \frac{f_{t}}{f_{m}^{\prime}}}
$$

Where;

$f_{t}=0.5187 f_{m}^{\prime} \frac{P_{d}}{\left(f_{m}^{\prime} A-1.683 P_{d}\right)}$ obtained by Mohr's failure theory ${ }^{4), 15)}$. $\left(P_{d}\right.$ and $A$ are the maximum diagonal compressive load and the masonry specimen section, respectively, obtained by diagonal test as shown in Fig.1).

$f^{\prime}{ }_{m}=$ the masonry compressive strength obtained by testing stack bonded prisms of five bricks according to the specifications of LUMB $1^{16}$ (see Fig.1).

The previous hypotheses concerning the failure brittleness and the diagonal cracking path remain applied for this case.

\section{b) Tie-columns effect}

When drift angles became large, tension in tiecolumns' reinforcement dominates on both directions of imposed lateral displacements. At such level, the 
cracked masonry panel pushes the tie-column sideward inducing tension in the reinforcing bars. In other words, the RC confining elements prevent the collapse of the masonry and cause additional compression stress in the vertical and horizontal directions; hence a certain amount of additional shear can be transmitted by dowel action of the vertical bars. This mechanism occurs mainly at wall corners.

According to Priestley and Bridgeman ${ }^{21)}$ in case of reinforced masonry walls, the dowel strength of vertical reinforcement crossing the crack can be estimated by assuming the reaction of a triangular pressure distribution of the grout (concrete) on the bars with a maximum value equal to $f_{c}$ (see Fig. 5a); while in this study, the idea of Priestley and Bridgeman can be correctly extended to the case of confined masonry walls if only the contribution of the stirrups composing the tie columns is added through their reactions $R_{s t}$ on the main bars as proposed and described in the Fig. 5a.

The vertical tie-columns significantly improve the ductility of masonry walls, but have a little effect on the lateral shear resistance ${ }^{5}$ (a maximum amount of $20 \%$ of the total shear resistance of the wall comes from both tie columns), then, it is more economic to reduce the web reinforcement ratio in tie-columns by increasing $S_{t}$ the distance between two successive stirrups. $S_{t}$ is usually considered equal to $(3 / 4) t^{22)}$ or simply to " $t$ "14), 22), where " $t$ " is the width of the

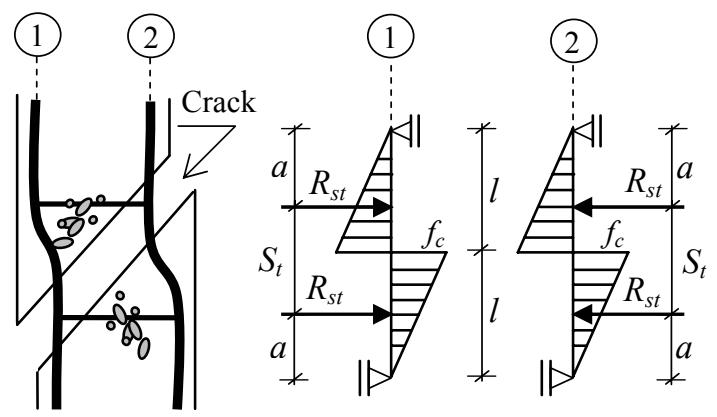

Fig. 5a Reactions of concrete and stirrups on main bars due to dowel phenomenon. tie-columns. It is also known that the shear cracks in the RC tie columns occurs at the four corners of the wall inclined by an approximate angle $\alpha=45^{\circ}{ }^{23}$.

According to the above reasoning, the shear crack would cross 1 or 2 stirrups at maximum (the stirrups are supposed positioned symmetrically from the inflection point of the bars presenting dowel action). The appropriate presentation of the dowel action phenomenon is clearly shown by the Fig. 5a. This will result in moment and shear force distributions of the form shown in Fig. 5b.

From the bending moment equilibrium:

$$
M_{\text {max }}=\frac{0.256}{f_{c} \phi} R_{c}^{2}+\frac{2 R_{s t}}{f_{c} \phi} R_{c}-\frac{R_{s t} S_{t}}{2}
$$

$M_{\max }=$ maximum external moment on the main bar.

$R_{c}=f_{c} \phi l / 2=$ reaction of the concrete on the main bar.

$f_{c}=$ compressive strength of concrete

$\phi=$ the main bar diameter

$R_{s t}=f_{y t} A_{s t}=$ reaction of the stirrup on the main bar.

$\left(f_{y t}\right.$ and $A_{s t}$ are the yield stress of stirrup and its section, respectively).

$S_{t}=$ distance between two successive stirrups.

Thus, since

$$
M_{\max , b}=z f_{y}=\frac{\pi \phi^{3}}{32} f_{y}
$$

$M_{\max , b}=$ maximum internal moment in the main bar. $f_{y}=$ yield stress of the main bar.

Equalizing the Eqs. (4) and (5) gives:

$$
\frac{0.256}{f_{c} \phi} R_{c}^{2}+\frac{2 f_{y t} A_{s t}}{f_{c} \phi} R_{c}-\frac{16 f_{y t} A_{s t} S_{t}+\pi \phi^{3} f_{y}}{32}=0
$$

After solving the Eq. (6) (determination of the value of $R_{c}$ ), the maximum value of shear resistance due to the dowel action of one single bar is obtained by the superposition of shear force diagrams shown
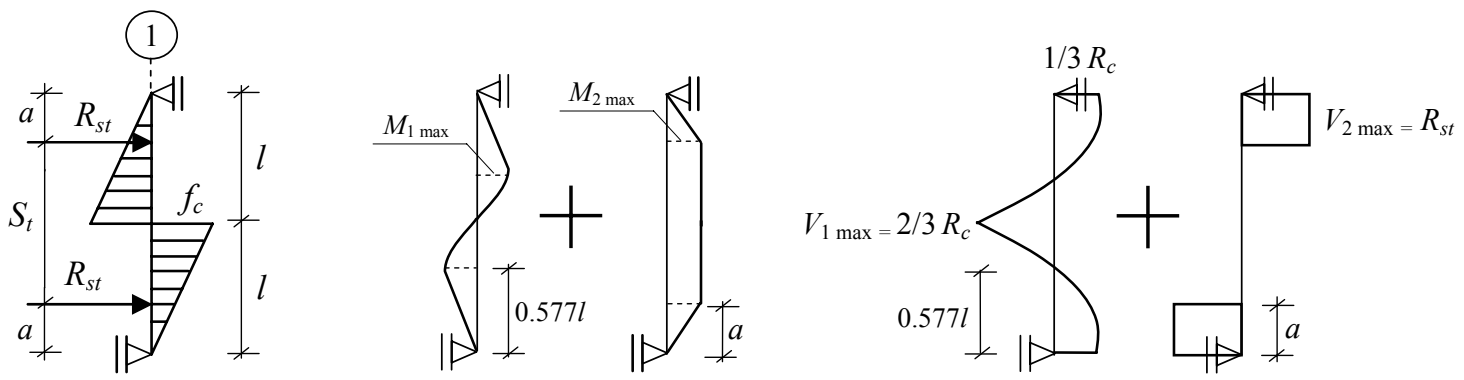

Fig. 5b Shear force and moment distributions along main bars undergoing dowel action. 
Table 1 Experimental and theoretical values of lateral loads and the corresponding displacements for the walls $\mathrm{CM}^{30 \mathrm{~J}}$ and $\mathrm{AH}^{*}$.

\begin{tabular}{|cccccccccccccc|}
\hline \multirow{2}{*}{ Spec. } & \multicolumn{3}{c}{$V_{e l}(\mathrm{kN})$} & \multicolumn{2}{c}{$V_{W}(\mathrm{kN})$} & \multicolumn{2}{c|}{$V_{f}(\mathrm{kN})$} & \multicolumn{2}{c|}{$\delta_{e l}(\mathrm{~mm})$} & \multicolumn{2}{c|}{$\delta_{W}(\mathrm{~mm})$} & \multicolumn{3}{c|}{$\delta_{f}(\mathrm{~mm})$} \\
\cline { 2 - 13 } & Exp. & Cal. & Exp. & Cal. & Exp. & Cal. & Exp. & Cal. & Exp. & Cal. & Exp. & Cal. \\
\hline CM30J-1 & 70.25 & 65.03 & 78.00 & 92.90 & 52.50 & 55.74 & 0.60 & 0.47 & 2.67 & 2.03 & 6.54 & 7.96 \\
CM30J-2 & 101.40 & 105.30 & 160.50 & 150.43 & 72.13 & 90.26 & 0.61 & 0.75 & 2.50 & 3.28 & 12.01 & 12.89 \\
AH $^{*}$ & 0.89 & 0.93 & 2.07 & 2.23 & 0.62 & 0.89 & 0.45 & 0.27 & 3.03 & 1.49 & 15.03 & 12.71 \\
\hline
\end{tabular}

${ }^{*}$ Average values of three confined walls AH-1, AH-2 and AH-3 after Tomaževič ${ }^{11)}$.

in Fig. 5b, where:

$$
V_{\max , b}=\max \left(2 / 3 R_{c}, 1 / 3 R_{c}+R_{s t}\right)
$$

Taking into account that, $R_{c}=f_{c} \phi l / 2$, the value of the dowel length $2 l$ is then deduced.

In case $2 l \leq S_{t}$ (stirrups positioned outside of the dowel length), the stirrups will not contribute to the shear resistance due to dowel mechanism, however, only the effect of concrete would be considered and the reaction of the concrete $R_{c}$ will be recalculated consequently.

The shear resistance of $n$ vertical bars, which represents the total resistance induced by the tiecolumns (confinements), is equal to:

$$
V_{c f}=\sum_{i=1}^{n} V_{\max , b i}
$$

In this experimental study $n$ is equal to eight bars.

The diagonal crack developed through the wall is assumed passing by the inflexion point of the steel bars of the confining columns which form dowels at the four corners of the wall. The shear force in the steel bars (coming from the dowel action) will be the force to be added to the shear resistance of the brick panel. As a result, the maximum shear resistance of a confined masonry wall $V_{W}$ is then:

1- Failure by critical tensile stress (principal tensile stress):

$$
V_{W}=V_{m}+V_{c f}=A_{m} \frac{f_{t}}{\beta} \sqrt{\frac{\sigma_{N}}{f_{t}}+1}+\sum_{i=1}^{n} V_{\max , b i}
$$

2- Failure by biaxial combination of principal stresses:

$$
\begin{gathered}
V_{W}=V_{m}+V_{c f}=\frac{A_{m}}{\beta\left(1+\frac{f_{t}}{f_{m}^{\prime}}\right)} \sqrt{f_{f}^{2}+\sigma_{N} f_{t}\left(1-\frac{f_{t}}{f_{m}^{\prime}}\right)-\sigma_{N}^{2} \frac{f_{t}}{f_{m}^{\prime}}} \\
+\sum_{i=1}^{n} V_{\max , b i}
\end{gathered}
$$

(2) Idealized hysteresis envelope curve and stiffness degradation

a) Hysteresis envelope curve

According to Tomaževič ${ }^{10)}$, the experimentally resistance envelope curve representing the relationship between the cyclic lateral load and the corresponding displacement, is idealized with a trilinear relationship. Three limit states are defined on the experimental curve using three pairs of parameters as follows:

- Elastic (crack) limit: determined by lateral load $\left(V_{e l}\right)$ and displacement $\left(\delta_{e l}\right)$ when the first significant crack in the wall appears and changes the initial stiffness.

- Maximum resistance: Noted by lateral load $\left(V_{W}\right)$ and displacement $\left(\delta_{W}\right)$ when the maximum resistance of the wall is reached.

- Ultimate (final) state: determined by lateral resistance $\left(V_{f}\right)$ and the maximum corresponding displacement $\left(\delta_{f}\right)$ just before collapse of wall.

$V_{e l}$ and $V_{f}$ are evaluated empirically ${ }^{10), 11)}$ where:

and

$$
V_{e l}=C_{c r} V_{W}
$$

$$
V_{f}=C_{s d} V_{W}
$$

$C_{c r}=$ reduction factor, vary from 0.6 to 0.8 .

$C_{s d}=$ strength degradation factor, vary from 0.4 to 0.8 .

$C_{c r}=0.7$ and $C_{s d}=0.6$ (average value of each interval) are considered in the calculation of $V_{e l}$ and $V_{f}$.

In the case where the contribution of tie-columns in the small deformation range is neglected ${ }^{11)}$, then in the Eq. (10) $V_{W}$ will be replaced simply by $V_{m}$.

The experimental and theoretical values of shear resistance are reported in the Table 1.

\section{b) Stiffness}

The element's stiffness depends on the mechanical properties of constituent materials, the geometry and boundary conditions.

When subjected to a lateral load $V$, a confined masonry wall generates a horizontal deflection $\delta$ 
(Fig.6). This lateral displacement is the sum of the deflection due to flexure and the deformation due to shear as defined in the Eq. (12a).

$$
\begin{gathered}
\delta=\frac{V h^{3}}{\alpha E_{e q v} I_{w}}+\frac{1.2 V h}{G_{e q v} A_{w}} \\
V=K_{e} \delta
\end{gathered}
$$

Where,

$K_{e}=$ the effective stiffness of the confined wall.

$I_{w}=t l^{3} / 12$, moment of inertia of the wall's cross section.

$A_{w}=$ area of the wall's horizontal cross section.

$1.2=$ the shear coefficient for rectangular cross-section.

$\alpha=$ coefficient depends on the boundary conditions $\alpha=3$ for cantilever panel and $\alpha=12$ in case of fixed-ended wall.

$E_{e q}=$ modulus of elasticity equivalent.

$G_{e q}=$ shear modulus equivalent

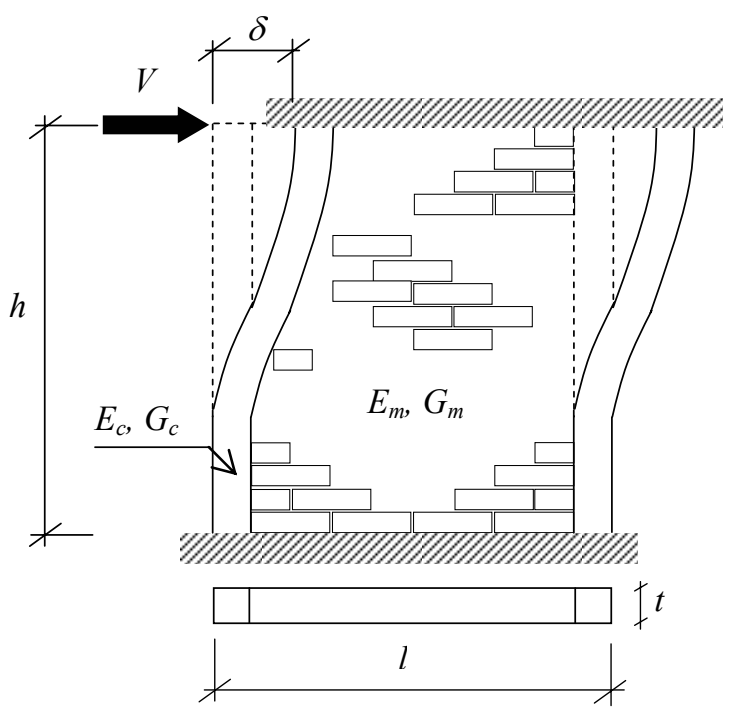

Fig. 6 Deformation of a fixed-ended confined masonry wall under lateral loading.

$$
\begin{aligned}
E_{\text {eqv }} & =\frac{E_{m} A_{m}+2 E_{c} A_{c}}{A_{m}+2 A_{c}} \\
G_{\text {eqv }} & =\frac{G_{m} A_{m}+2 G_{c} A_{c}}{A_{m}+2 A_{c}}
\end{aligned}
$$

After substituting the value of $V$ from Eq. (12b) into Eq. (12a) and rearranging its different terms, the general equation for the effective stiffness of confined masonry wall in the elastic domain is obtained and expressed as follows:

$$
K_{e}=\frac{G_{e q v} A_{w}}{1.2 h\left[1+\mu \frac{G_{e q v}}{E_{e q v}}\left(\frac{h}{l}\right)^{2}\right]}
$$

$\mu=$ coefficient describes the applied restraint conditions of the wall, $\mu=3.33$ for cantilever walls and $\mu=0.83$ in case of a fixed-ended walls.

In the plastic range, however, secant stiffness $K$ is calculated as a function of effective stiffness $K_{e}$ and the index damage $I_{d}{ }^{10), 11)}$.

$$
K=K_{e}-\sqrt{a I_{d}-b}
$$

$a, b=$ stiffness degradation parameters ${ }^{10), 11) .}$

$I_{d}=$ Index damage defined as following:

$I_{d}=0.25$ : the appearance of the first significant diagonal crack in the wall (crack limit).

$I_{d}=0.50$ : a network of diagonally oriented cracks. Usually, when the maximum resistance is achieved. $I_{d}=0.75$ : increased width of cracks. Crushing of masonry units in the middle of the wall, splitting of units and grout at the compressed zones of the wall. $I_{d}=1.00$ : heavy damage (beyond repair) or collapse of the wall. As has been found by the analysis of experimental results ${ }^{10)}$, just before, or at $I_{d}=1.00$, secant stiffness accounts only with 2 to $5 \%$ of the wall's effective stiffness $K_{e}$.

According to the experimental test conditions, $K_{e}$ corresponds to $I_{d}=0.25$ and the final (ultimate) se-

Table 2 Secant stiffness and stiffness degradation at singular points of hysteresis envelops for the specimens CM30J and AH*

\begin{tabular}{|ccccccccccc|}
\hline \multirow{2}{*}{ Spec. } & \multicolumn{2}{c}{$K_{e}(\mathrm{kN} / \mathrm{mm})$} & \multicolumn{2}{c|}{$K_{W}(\mathrm{kN} / \mathrm{mm})$} & \multicolumn{2}{c|}{$K_{f}(\mathrm{kN} / \mathrm{mm})$} & \multicolumn{2}{c|}{$K_{W} / K_{e}$} & \multicolumn{2}{c|}{$K_{f} / K_{e}$} \\
\cline { 2 - 10 } CM30J-1 & Exp. & Cal. & Exp. & Cal. & Exp. & Cal. & Exp. & Cal. & Exp. & Cal. \\
\hline CM30J-2 & 116.60 & 139.45 & 29.20 & 45.80 & 8.00 & 7.00 & 0.25 & 0.33 & 0.07 & 0.05 \\
AH $^{*}$ & 166.23 & 139.45 & 64.20 & 45.80 & 6.01 & 7.00 & 0.38 & 0.33 & 0.04 & 0.05 \\
& 1.66 & 3.45 & 0.64 & 1.5 & 0.04 & 0.07 & 0.38 & 0.43 & 0.02 & 0.02 \\
\hline
\end{tabular}

* Average values of three confined walls AH-1, AH-2 and AH-3 after Tomaževič ${ }^{11)}$. 
cant stiffness corresponds to $I_{d}=0.75$, which represents an amount of $5 \%$ of $K_{e}$ as shown in the Table2.

The stiffness degradation parameters $a$ and $b$ equal to 1.805 and 0.451 are obtained when these two boundary conditions $\left(K=K_{e} \quad, \quad I_{d}=0.25\right) \quad$ and $\left(K=K_{f}=5 \% K_{e}, I_{d}=0.75\right)$ are replaced simultaneously into Eq. (15). In this respect, Eq. (15) becomes:

$$
K=K_{e}\left(1-\sqrt{1.805 I_{d}-0.451}\right)
$$

In this study, secant stiffness of walls is calculated at three defined stages (crack limit, maximum and ultimate loading). In the order to estimate the stiffness degradation of confined walls, the ratios $K_{w} / K_{e}$ and $K_{f} / K_{e}$ were experimentally and analytically cal-

Table 3 Comparison between the experimental lateral resistances obtained from literature and the calculated values according to the proposed approach.

\begin{tabular}{|c|c|c|c|c|c|c|}
\hline \multirow[b]{2}{*}{ Wall ref. } & \multicolumn{2}{|c|}{ Wall size } & \multirow[b]{2}{*}{ Brick type } & \multirow[b]{2}{*}{$h / l$} & \multirow[b]{2}{*}{$\begin{array}{c}\sigma_{N} \\
(\mathrm{MPa})\end{array}$} & \multirow[b]{2}{*}{ Nota } \\
\hline & $\begin{array}{l}\text { Brick panel } \\
h \times l \times t(\mathrm{~cm})\end{array}$ & $\begin{array}{l}\text { Column } \\
e \times t(\mathrm{~cm})\end{array}$ & & & & \\
\hline Wall-1 ${ }^{24)}$ & $220 \times 80 \times 14$ & $20 \times 14$ & Hollow ceramic & 2.75 & 0 & \multirow[b]{2}{*}{ Wall-1 \& 2 are similar } \\
\hline Wall-2 24) & $220 \times 80 \times 14$ & $20 \times 14$ & Hollow ceramic & 2.75 & 0 & \\
\hline $\mathrm{B}-0^{25)}$ & $220 \times 200 \times 13.5$ & $20 \times 13$ & Perforated clay brick & 1.10 & 0 & Mortar C:Cal: $S: W=1: 0: 5: 2$ \\
\hline B-1 25$)$ & $220 \times 200 \times 13.5$ & $20 \times 13$ & Perforated clay brick & 1.10 & 0 & Mortar C:Cal: $\mathrm{S}: \mathrm{W}=1: 1: 5: 2$ \\
\hline$C-0{ }^{25)}$ & $220 \times 200 \times 13.5$ & $20 \times 12$ & Hollow clay brick & 1.10 & 0 & Mortar C:Cal: $\mathrm{S}: \mathrm{W}=1: 0: 5: 2$ \\
\hline$C-1{ }^{25)}$ & $220 \times 200 \times 13.5$ & $20 \times 12$ & Hollow clay brick & 1.10 & 0 & Mortar C:Cal: $\mathrm{S}: \mathrm{W}=1: 1: 5: 2$ \\
\hline Spec. $B^{26)}$ & $133 \times 87 \times 10$ & $20 \times 10$ & Solid clay brick & 1.50 & 0.30 & $6 \mathrm{D} 13 ; S_{t}=22 \mathrm{~cm}$ \\
\hline Spec. $C^{26)}$ & $133 \times 87 \times 10$ & $20 \times 10$ & Solid clay brick & 1.50 & 0.30 & Main bars $4 \mathrm{D} 8 ; S_{t}=5 \mathrm{~cm}$ \\
\hline Spec. I ${ }^{27)}$ & $133 \times 87 \times 10$ & $10 \times 10$ & Solid clay brick & 1.50 & 0.40 & $4 \mathrm{D} 8$, Stirrups D4, $S_{t}=4 \mathrm{~cm}$ \\
\hline Wall-19 ${ }^{28)}$ & $220 \times 200 \times 14$ & $20 \times 14$ & Hollow concrete & 1.10 & 0.42 & Hollow concrete - type 1 \\
\hline Wall-20 ${ }^{28)}$ & $220 \times 200 \times 14$ & $20 \times 14$ & Hollow concrete & 1.10 & 0.42 & Hollow concrete - type 2 \\
\hline MV3 ${ }^{29)}$ & $210 \times 175 \times 13$ & $20 \times 13$ & Perforated clay brick & 1.20 & 0.54 & \\
\hline Spec. $\mathrm{P}^{27)}$ & $133 \times 87 \times 10$ & $10 \times 10$ & Solid clay brick & 1.50 & 0.70 & Similar remark as Spec. I \\
\hline MV5 $^{29)}$ & $210 \times 175 \times 13$ & $20 \times 13$ & Perforated clay brick & 1.20 & 0.89 & \\
\hline Spec. $Q^{27)}$ & $133 \times 87 \times 10$ & $10 \times 10$ & Solid clay brick & 1.50 & 1.40 & Similar remark as Spec. I \\
\hline & & By applying & Eq. (9a) & & applyi & g Eq. (9b) \\
\hline Wall ref. & $\begin{array}{l}V_{W \text { Exp. }} \\
(\mathrm{kN})\end{array}$ & $\begin{array}{l}V_{W \text { Cal. }} \\
(\mathrm{kN})\end{array}$ & $V_{\text {Cal. }}-V_{W \text { Exp. }} . / V_{W \text { Exp. }} \mid \%$ & $\begin{array}{r}V_{W} \\
(\mathrm{k}\end{array}$ & & $\left.V_{W \text { Cal. }}-V_{W \text { Exp. }}\right) / V_{W \text { Exp. }} \mid \%$ \\
\hline Wall-1 ${ }^{24)}$ & 107.00 & 108.70 & 1.58 & 116 . & & 9.23 \\
\hline Wall-2 ${ }^{24)}$ & 101.00 & 108.70 & 7.62 & 116. & & 15.72 \\
\hline $\mathrm{B}-0^{25)}$ & 158.18 & 209.76 & 32.61 & 263. & & 66.62 \\
\hline $\mathrm{B}-1^{25)}$ & 195.00 & 194.87 & 0.07 & 238. & & 22.05 \\
\hline $\mathrm{C}-0^{25)}$ & 191.23 & 200.20 & 4.70 & 237. & & 24.30 \\
\hline $\mathrm{C}-1^{25)}$ & 171.00 & 197.36 & 15.42 & 235 . & & 37.52 \\
\hline Spec. B ${ }^{26)}$ & 235.00 & 273.54 & 16.40 & 300. & & 27.96 \\
\hline Spec. $C^{26)}$ & 167.00 & 178.54 & 6.91 & 205. & & 23.17 \\
\hline Spec. I ${ }^{27)}$ & 122.00 & 118.32 & 3.00 & 138. & & 13.28 \\
\hline Wall-19 ${ }^{28)}$ & 190.00 & 244.58 & 28.73 & 257. & & 35.52 \\
\hline Wall-20 ${ }^{28)}$ & 186.00 & 242.72 & 30.50 & 259. & & 39.27 \\
\hline MV3 ${ }^{29)}$ & 220.45 & 180.65 & 18.05 & 196. & & 10.90 \\
\hline Spec. $P^{27)}$ & 141.00 & 125.43 & 11.04 & 142. & & 0.92 \\
\hline MV5 ${ }^{29)}$ & 227.00 & 202.84 & 10.64 & 211. & & 6.73 \\
\hline Spec. $Q^{27)}$ & 176.00 & 140.00 & 20.45 & 150. & & 14.53 \\
\hline
\end{tabular}




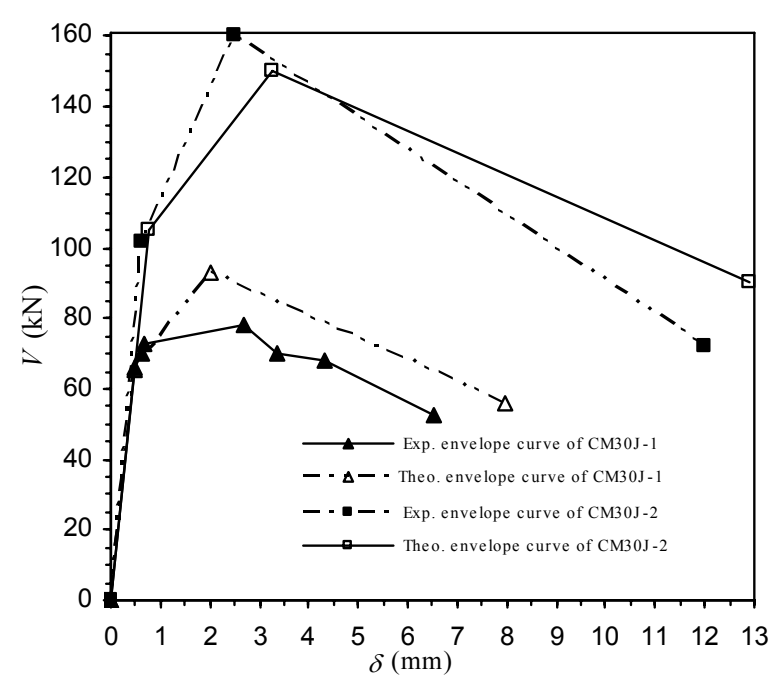

Fig. 7 Experimental and calculated lateral resistance envelopes of the wall CM30J-1 and CM30J-2.

culated, their values are summarized in Table 2.

\section{DISCUSSION AND CONCLUSION}

By applying Eq. (9a) to specimen CM30J-1 characterized by a moderate gravity load $(0.4 \mathrm{MPa})$, on show clearly that the masonry brick panel itself contributes to $80 \%$ to the total shear capacity $\left(V_{m}=\right.$ $73.7 \mathrm{kN}$ ), while the remaining $20 \%$ comes from the tie-columns $\left(V_{c f}=19.2 \mathrm{kN}\right)$, which is in ac- cordance with Umek ${ }^{5}$.

Results summarized in Table 1 reveal that the calculated value of the shear force at the crack limit $V_{e l}$ is underestimated by $7.4 \%$ as to test data, while the total shear $V_{W}$ and the final resistance $V_{f}$ are overestimated by $19.1 \%$ and $6.2 \%$, respectively.

The maximum shear resistance in the case of the confined masonry wall CM30J-2 is calculated by Eq. (9b) instead of Eq. (9a) because this equation is more appropriate when an important gravity load is applied. The Eq. (9b) underestimates the shear resistance by only $6.27 \%$ while if the Eq. (9a) is used the underestimation becomes $12.77 \%$.

The lateral load was affected by the intensity of the gravity load. The maximum experimental lateral load increased by two times $\left(V_{W \exp \text { CM30J-2 }}=2 V_{W \exp \text { CM30J-1 }}\right)$ when the gravity load increased from $0.4 \mathrm{MPa}$ to 1.4 $\mathrm{MPa}$, whereas, the theoretical calculations reveal an increase of 1.6 times.

It is worth to notice that the elastic limit force of the specimen CM30J-2 is overestimated by $3.8 \%$ while the final resistance $V_{f}$ is overestimated by $25.1 \%$, and the participation of the tie columns themselves count for $29.1 \%$ of the total lateral shear resistance $\left(V_{f}=\right.$ $43.82 \mathrm{kN})$.

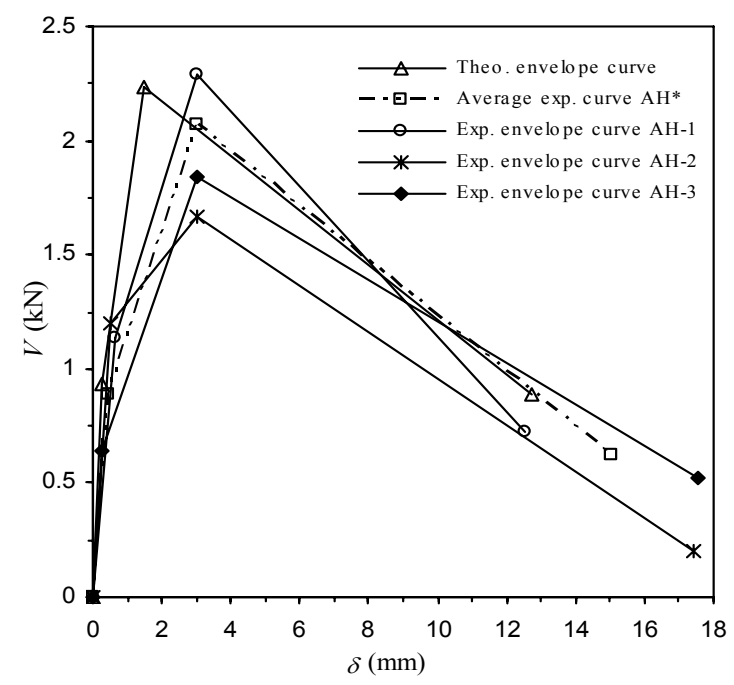

Fig. 8 Experimental and calculated lateral resistance envelopes of walls $\mathrm{AH}-1, \mathrm{AH}-2$ and $\mathrm{AH}-3^{11)}$.

The specimen CM30J-2, with a different applied gravity load, underwent shear failure in much the same as exhibited by the specimen CM30J-1.

As well known for masonry structural members, there are many factors that influence their resistance; such as the heterogeneity caused by join mortars and the variability of the compressive strength of brick units. It is of importance to mention that several masonry codes in the world such as Eurocode $6^{1)}$ or RPA99 ${ }^{3)}$ propose a partial safety factor " $\gamma_{M}$ " which reduces the tensile and the compression strengths of the masonry, thus the shear strength of the brick wall.

In the case of walls AH-1, AH-2 and AH-3 made at $1: 5$ scale $^{11)}$, RC ties effect is estimated at $40 \%$ of the total shear resistance. The crack limit, the maximum and the final shear forces were overestimated by 4.5 $\%, 7.7 \%$ and $43 \%$, respectively. According to the obtained results it is concluded that the predicted shear capacity $V_{W}$ using the proposed approach correlates adequately with the rough experimental values of the tested walls CM30J-1 and CM30J-2 as well as for the specimens obtained from literature ${ }^{11)}$ (AH-1, $\mathrm{AH}-2$ and $\mathrm{AH}-3)$. In fact, the induced maximum shear capacity of walls was predicted with an error of $7.7 \%$, while Tomaževič and Klemenc estimated the same shear capacity with an average error of $38.7 \%$ for the same tested specimens.

The stiffness ratios $\left(K_{w} / K_{e}\right)_{\text {exp. }}=0.25$ and $\left(K_{w} / K_{e}\right)_{\text {cal. }}=0.33$ of the specimen CM30J-1 as presented in Table 2, show clearly the degradation of the stiffness in the interval located between the crack limit and the maximum lateral loading. In other words, at the attained maximum lateral loading, the experimental and the theoretical effective stiffness $K_{e}$ are decreased by $75 \%$ and $67 \%$, respectively. 
In the post-peak (see Fig.7) the confined wall continue to carry the vertical load at large displacement amplitudes, despite substantial damage that has been caused to the wall at repeated lateral load reversals. At the final stage (ultimate stage), the secant stiffness is $7 \%$ of the effective stiffness $K_{e}$ which is in accordance with the predicted value $K_{f}=5 \% K_{e}$ (following the classification of the degree of damage illustrated before).

The degradation of the elastic stiffness in case of the specimen CM30J-2 can be considered similar to the case of the specimen CM30J-1 when the peak was reached.

Regarding $\mathrm{AH}$ walls, the stiffness at maximum attained load $K_{w}$ is $62 \%$ of the effective stiffness $K_{e}$ of the experimental data while analytically the value is $57 \%$. As to the ultimate stiffness $K_{f}$ the experimental value matches the predicted one which is equal to $2 \%$.

The general applicability of the proposed approach regarding the maximum lateral resistance was confirmed by a good correlation between calculated values and experimental data of previous published works of various confined masonry walls of different characteristics and material properties as given in Table 3 (brick unit type, concrete and mortar strengths, column section, reinforcing details, $h / l$ ratio and gravity load). The calculation of lateral resistance of specimens without any gravity load or carrying a small to a moderate gravity load reveals that Eq. (9a) gives an average error of $13.4 \%$ contrary to Eq. (9b) which gives an average error of 28.6 $\%$, almost two times greater than the value obtained from the previous equation. As for specimens carrying a high gravity load (MV3, Spec. P, MV5 and Spec. Q), Eq. (9a) gives an average error of $15 \%$ while Eq. (9b) gives an error of $8.3 \%$ only. It has been observed that the critical stress value of the vertical load which separates the low gravity loading and the high gravity loading is located into the interval of $0.42 \mathrm{MPa}$ to $0.54 \mathrm{MPa}$ (refer to Table 3 ), the determination of the exact value of this stress requires more experimental tests of walls in that range. Furthermore, according to the Peruvian masonry $\operatorname{code}^{20)}$ which limits the confined masonry buildings to five stories, the exterior walls are less loaded than the interior walls where the maximum gravity load is estimated to $0.5 \mathrm{MPa}$.

Based on the common gravity load relative to five story masonry buildings adopted in Chile and Peru also, the value of $0.5 \mathrm{MPa}$ seems appropriate as an upper limit for small to moderate loaded walls. This value also can be considered as a median value for the interval $0.42 \mathrm{MPa}$ to $0.54 \mathrm{MPa}$ corresponding to the data given in Table 3.
In this study, it is assumed that the failure in the brick panel is brittle and occurs by diagonal splitting and not by joint separation. The approach is based on predicting the diagonal cracking strength, considered as the shear capacity of the brick panel and an amount of shear coming from the tie-columns. In this type of structural members, tie-columns are used mainly to provide post-cracking deformation capacity by maintaining the integrity of the masonry after diagonal cracking.

The proposed method has been found satisfactory through the participation of the tie-columns in the maximum resistance of the wall and by an additional deformation in the post-cracking. The modeling is based on the dowel action including an additional effect of the stirrups.

ACKNOWLEDGMENT: The experimental work was supported by Japan International Cooperation Agency (JICA), and carried out at the Building Research Institute (BRI) in Tsukuba-Japan.

The advice of Dr. Hassane Ousalem from the University of Tokyo and the continuous help of Prof. Masaru Kitaura, Dr. Toshikazu Ikemoto and Dr. Akira Murata from Earthquake Engineering Laboratory of Kanazawa University, are well acknowledged.

\section{REFERENCES}

1) Eurocode 6. Design of masonry structures. part 1-1. : General rules for buildings. Rules for reinforced and unreinforced masonry, ENV 1996-1-1: 1995, 1995.

2) Eurocode 8. Design provisions for earthquake resistance of structures. part 1-3. : General rules - Specific rules for various materials and elements. ENV 1998-1-3: 1995, 1995.

3) CGS. : Règles Parasismiques Algériennes, RPA99/ver. 2003, D.T.R. - B.C. 2.48 .

4) Sucuoğlu, H. and McNiven, H. D. : Seismic shear capacity of reinforced masonry piers, J. Struct. Engrg., Vol. 117, No. 7, pp. 2166-2186, 1991.

5) Umek, A.: Comparaison between unreinforced, confined and horizontally reinforced masonry walls, Civil Engrg. J., Vol. 20 (Society of Civil Engineers, Ljubljana), pp. 241-248, 1971.

6) Meli, R. : Behavior of masonry walls under lateral loads, Proc. of 5th World Conf. Earthquake Engrg., Paper 101a., 1973.

7) Aguila, V., Delfin, F. and Astroza, M. : Estudio experimental de soluciones de reparación y refuerzo para elementos de albañilería, Pub. SES I 1/88 (221), Universidad de Chile, Santiago, 1988.

8) Bolong, Z., Mingshun, W. and Deyuan, Z. : Shaking table study of five-story unreinforced block masonry model building strengthened with reinforced concrete columns and tie bars, Proc. US-PRC Joint Workshop on Seismic Resistance of Masonry Struct., pp. IV-11-1-11, Harbin, 1988.

9) Wenzhong, Y. and Zhaohong, J. : Functions of ties concrete columns in brick walls, Proc. of 9th World Conf. Earthquake Engrg., Vol. 6, pp. VI-139-144, 1988. 
10) Tomaževič, M. : Earthquake-resistant Design of Masonry Buildings (Innovation in Structures and Construction, Vol. I), Imperial college press, 1999.

11) Tomaževič, M. and Klemenc, I. : Seismic behaviour of confined masonry walls, Earthquake Engrg. Struct. Dynamics, Vol. 26, pp. 1059-1071, 1997.

12) Dangol, P., Hori, N., Inoue, N., Nishida, T. and Kobayashi, J. : Analytical studies on seismic resistance of composite block masonry wall by rigid body spring model, J. Struct. Engrg., Vol. 49B, pp.243-250, 2003.

13) Hori, N., Inoue, N., Dangol, P., Nishida, T. and Kobayashi, J.: Experimental and analytical studies on earthquake resisting behaviour of confined concrete block masonry structures, Earthquake Engrg. Struct. Dynamics, Vol. 35, pp. 1699-1719, 2006.

14) Goto, T., Mizuno, H., Iiba, M. and Kato, H. : Cyclic loading tests of confined masonry walls, Research report, B.R.I, Tsukuba, Japan, March 1993.

15) Yokel, F. Y., and Fattal, S, G. : Failure hypothesis for masonry shear walls, J. Struct. Div., ASCE, Vol. 102, No. 3, pp. 515-532, 1976

16) Rilem. Technical recommendations for the testing and use of constructions materials, LUMB1, Compressive strength of small walls and prisms, 1994 (b).

17) Chiostrini, S., Galano, L. and Vignoli, A.: On the determination of strength of ancient masonry walls via experimental test, Proc. of 12th World Conf. Earthquake Engrg., CD-ROM, 2000.

18) Sucuoğlu, H. and Erberik, A.: Performance evaluation of three-storey unreinforced masonry building during the 1992 Erzincan earthquake, Earthquake Engrg. Struct. Dynamics, Vol. 26, pp. 319-336, 1997.

19) Timoshenko, S. : Strength of materials, Chap. 10, part II, $3^{\text {rd }}$ ed., D. Van Nostrand Co. Inc., Princeton, N.J., 1956.

20) Reglamento Nacional de Edificaciones. Norma E 070 Albañilería, Perú, 2006.

21) Priestley, M.J.N. and Bridgeman, D.O. : Seismic resistance of brick masonry walls, Bull. of the New Zealand Nat. Soc. for Earthquake Engrg., Vol. 7, No. 4 (New Zealand National
Society for Earthquake Engineering, Wellington), pp. 167-187, 1974.

22) Yoshimura, K., Kikuchi, K., Okamoto, T. and Sanchez, T. : Effect of vertical and horizontal wall reinforcement on seismic behavior of confined masonry walls, Proc. of 11th World Conf. Earthquake Engrg. (11 ${ }^{\text {th }}$ WCEE), CD-ROM, No. 191, 1996.

23) Pillai, S.U. and Kirk, D.W. : Reinforced concrete design, Canadian Cataloguing in Publication Data, $2^{\text {nd }}$ ed., 1988.

24) Diez, J., Astroza, M. and Delfin, F. : Estudio experimental de modalidades de refuerzo para muros de albañilería de unidades cerámicas, Jornadas en español y portugués sobre estructuras y materiales, Madrid, España, Vol. VI, pp. 319-338, 1988.

25) San Bartolomé, A. : Ensayos de carga lateral en muros de albañilería confinados por elementos de concreto armado-Correlación de resultados entre especimenes a escala natural y pequeñas probetas, Ponencia al V Congreso Nacional. de Ingeniería Civil, Tacna, Perú, 1983.

26) Kato, H., Goto, T. and Mizuno, H. : Cyclic loading tests of confined masonry wall elements for structural design development of apartment houses in the third world, Proc. of 10th World Conf. Earthquake Engrg. (10 ${ }^{\text {th }}$ WCEE), Balkema Rotterdam, pp.3539-3544, 1992.

27) Goto, T., Mizuno, H., Iiba, M. and Kato, H. : Structural characteristics of confined masonry wall : Part 3 quasi static loading test-effect of lateral reinforcements in brick walls, Sum. of tech. papers of Annual meeting AIJ, Structures II, Vol.1994(19940725), pp. 1869-1870, 1994.

28) Muñoz, W. : Estudio experimental del comportamiento de muros de albañilería de bloques de hormigón sometidos a carga lateral alternada, Civil Eng. Thesis, Universidad de Chile, 1992.

29) San Bartolomé, A. and Echeverria, G. : Ensayos de carga lateral en muros de albañilería confinada-Efectos de la carga vertical, Ponencia al VI Congreso Nacional. de Ingeniería Civil, Cajamarca, Perú, 1986.

(Received June 7, 2007) 